\title{
Selected Socioeconomic Characteristics of Waste Collector Children in Dhaka City
}

Mohammad Saeed Hossain

Department of Economics

East West University

Dhaka, Bangladesh

Email: saeedhossainbd@gmail.com

Md. Mahmudul Alam*

Senior Lecturer

School of Economics, Finance \& Banking (SEFB)

College of Business (COB)

Universiti Utara Malaysia (UUM)

Sintok, Kedah, Malaysia

Email: rony000@gmail.com

Niaz Ahmed Khan

Professor and Chairman

Department of Development Studies,

University of Dhaka, Bangladesh

Email: niaz.khan@yahoo.com

* corresponding author

\section{Citation Reference:}

Hossain, M.S., Alam, M.M., and Khan, N.A. 2016. Selected Socioeconomic Characteristics of Waste Collector Children in Dhaka City. Development Review, Vol. 25, 23-32. (online) http://napd.portal.gov.bd/site/files/0a713ea2-ef24-4ce8-bd1e-6bf15d5ded40

[publisher - National Academy for Planning and Development, Ministry of Planning, Government of Bangladesh]

This is a pre-publication copy.

The published article is copyrighted by the publisher of the journal. 


\title{
Selected Socioeconomic Characteristics of Waste Collector Children in Dhaka City
}

\author{
Mohammad Saeed Hossain \\ Md. Mahmudul Alam \\ Niaz Ahmed Khan
}

\begin{abstract}
Generally in the city areas of developing countries, children from the poor and low income families are involved in a range of risky, unhealthy, and environmentally hazardous economic activities and trades. One of these common activities concerns collecting recyclable waste form the street or landfill areas. To understand the socioeconomic characteristics of these waste collector children, this study collected data from fifty children who engaged in waste collection in the landfill of Matuail in Dhaka City, Bangladesh. The data were collected by questionnaire guide, and the samples were selected based on convenient random sampling. This study analyses the socioeconomic conditions of these waste collector children by focussing on such characteristics as their demographic profile, economic affiliation, and nature of the waste collection task. This empirical study may inform and illuminate the relevant policy makers and field activists in widening their understanding of the life and living of this vulnerable group.
\end{abstract}

Key Words: Waste; Landfill; Street Children; Poverty; Bangladesh JEL Code: I31, I32

\section{Introduction}

It is now unequivocally established that street children constitute one of the most vulnerable and disadvantaged segments of the population in the developing world including Bangladesh. UNICEF (1990) estimated that there were 369 million poor children under age 15 in the cities of the developing world during the 1980s. A significant number of them are considered as street children engaged in many risky and hazardous activities. These children are also routinely deprived of the basic needs which are now universally accepted as fundamental entitlement and right for human beings.

In developing countries, waste management often remains unregulated, and it is easy for disadvantaged children to end up getting involved in this hazardous sector. There are global evidences to this effect. Landrigan et al. (1998), for example, found that many waste pickers are mainly children and women in developing countries - working mostly in open dumps. Shah (2007) found that the street children (mostly belonging to very poor families) collect waste from waste bins and open waste heaps, and they contribute economically to their families for survival. WIEGO (2013) showed that waste pickers and other recycling and waste workers in the informal economy have offered a public service with positive economic, social and environmental impact for their communities.

The vulnerability and hazard dimension of street children's waster-related engagement has received particular attention in the recent years. Sarkar (2003) focused on the socio-economic and occupational health aspects the waste pickers of Delhi, and recommended developing a set of skills especially among the public service officials targeted towards ensuring and facilitating the resolution of fundamental problems of the waste 
pickers, associated with oppressive working conditions, poor returns, exploitation and their everyday harassments. Similarly, referring to the programs with street-involved children and youth studied in Kenya, Kilbride et al. (2000) claims, "indeed, a good case can be made that all current programs collectively serve to perpetuate the problem rather than to reduce the number of street children and improve the quality of their live".

In Bangladesh, where more than $30 \%$ of the people live in extreme poverty, many families are unable to meet their basic needs, resulting in forcing them to engage their children in hazardous tasks and trades at an early age. One of the important economic activities of these children is waste collection from street and landfills. Working in such dangerous situation is very risky for these children. They are not aware about the health risk and also do not take enough precaution. They also typically receive bare minimum facilities and securities from the task managers - for example including landfill authority.

Khan (2000) findings expose that in terms of age, family size, parents' occupation and income, level of education etc., child laborers of Dhaka city are not enjoying a good environment. Life and living situations, job and working positions are too breakable of a child labor. By doing hard labor they cannot change their life style but situation compels them to pass the everyday life in a miserable condition.

Understanding the socioeconomic background, context, and nature of these children is important to identify and reckon the extent and nature of their vulnerability of the group, and take ameliorative action accordingly to ensure child rights and poverty eradication. In this backdrop, this study is an attempt to understand the socioeconomic profile of these children engaging in waste collection in Dhaka City, Bangladesh. This study was conducted on 50 children - identified through a Convenient Random Sampling technique -who engaged in waste collection from the Matuail landfill of Dhaka city in Bangladesh. Data were collected during the period between September and November 2013 by using a semi-structured questionnaire. Additionally, four focused group discussions were held in the study area with an interval of 8 days between the FGDs.

After this general introduction, the following text is divided into two broad sections. The next section presents the key findings of the study together with the associated discussion and analysis. The concluding section recapitulates and main observations of the study and furnishes some recommendations.

\section{Findings \& Discussion}

\section{Demographic Profile of Waste Collector Children}

\section{i. Age and Gender}

The survey was conducted among 50 respondents, where $40 \%$ were female and $60 \%$ were male (Table 1). The age of the respondents ranged from 8-15 years. Almost half of the respondents are from the age group of 14 to 15 years. The minimum age of the female respondents is 9 and male is 8 years and maximum age for the male and females is 15 years.

Table 1: Age of waste collector children

\begin{tabular}{lll}
\hline Gender & Age & Total \\
\cline { 2 - 3 }
\end{tabular}




\begin{tabular}{cccccccccc} 
& \multicolumn{1}{c}{8} & 9 & 10 & 11 & 12 & 13 & 14 & 15 & \\
\hline Female & $0(0 \%)$ & $1(2 \%)$ & $2(4 \%)$ & $0(0 \%)$ & $5(10 \%)$ & $3(6 \%)$ & $7(14 \%)$ & $2(4 \%)$ & $20(40 \%)$ \\
Male & $4(8 \%)$ & $0(0 \%)$ & $3(6 \%)$ & $3(6 \%)$ & $3(6 \%)$ & $3(6 \%)$ & $6(12 \%)$ & $8(16 \%)$ & $30(60 \%)$ \\
\hline Total & $4(8 \%)$ & $1(2 \%)$ & $5(10 \%)$ & $3(6 \%)$ & $8(16 \%)$ & $6(12 \%)$ & $13(26 \%)$ & $10(20 \%)$ & $50(100 \%)$ \\
\hline
\end{tabular}

\section{ii. Schooling}

Among the respondents, almost all of the children have primary education (98\%). Those who are going to school, go to either a government primary school or an NGO school operated by the Gram Bangla. The NGO provides free food and education instruments to the children who are going to that school. From the total, $62 \%$ of the children go to an NGO school and $36 \%$ of the children go to a government primary school. $32 \%$ of the female children go to an NGO school and $8 \%$ go to a government school. $30 \%$ of the male children go to an NGO school and $28 \%$ of the male children go to a government school. Overall, the female children prefer the NGO school compared to the government school.

\section{iii. Family Member}

Among the respondents, half of them are living in a family with four members (Table 2). The average family size of the respondents is 4.16 members. Among the respondents, 20 families have 3 earning members and 17 families have 4 earning members. In each family, there are on an average 3.08 members earning for their family.

Table 2: Family earning member of the waste collector children

\begin{tabular}{ccccc}
\hline \multirow{2}{*}{ Family size } & \multicolumn{3}{c}{ Earning member } & \multirow{2}{*}{ Grand Total } \\
\cline { 2 - 4 } & 2 & 3 & 4 & \\
\hline 2 & $4(8 \%)$ & $0(0 \%)$ & $0(0 \%)$ & $4(8 \%)$ \\
3 & $6(12 \%)$ & $1(2 \%)$ & $0(0 \%)$ & $7(14 \%)$ \\
4 & $3(6 \%)$ & $10(20 \%)$ & $10(20 \%)$ & $23(46 \%)$ \\
5 & $0(0 \%)$ & $7(14 \%)$ & $4(8 \%)$ & $11(22 \%)$ \\
6 & $0(0 \%)$ & $1(2 \%)$ & $2(4 \%)$ & $3(6 \%)$ \\
7 & $0(0 \%)$ & $1(2 \%)$ & $1(2 \%)$ & $2(4 \%)$ \\
\hline Grand Total & $13(26 \%)$ & $20(40 \%)$ & $17(34 \%)$ & $50(100 \%)$ \\
\hline
\end{tabular}

\section{iv. Housing}

All of the respondents are living in rented houses, where their monthly average rent is BDT 2,213 (Table 3). The range of the monthly rent of the respondents is from BDT 1,100 to BDT 3,500 . Majority $(64 \%)$ of them are living in a tin shed house, while $22 \%$ respondents are living in a mixed house of bamboo and other elements, while $14 \%$ respondents are living in brick built houses.

Table 3: The house rent of the waste collector children

\begin{tabular}{ccccc}
\hline Rent per & \multicolumn{3}{c}{ Type of Residence } & \multirow{2}{*}{ Grand Total } \\
\cline { 2 - 4 } month & Brick & Tin Shed & Mixed & \\
\hline $1100-1500$ & $0(0 \%)$ & $1(2 \%)$ & $7(14 \%)$ & $8(16 \%)$ \\
$1600-2000$ & $0(0 \%)$ & $10(20 \%)$ & $4(8 \%)$ & $14(28 \%)$ \\
$2100-2500$ & $1(2 \%)$ & $15(30 \%)$ & $0(0 \%)$ & $16(32 \%)$ \\
$2600-3000$ & $5(10 \%)$ & $6(12 \%)$ & $0(0 \%)$ & $13(26 \%)$ \\
$3100-3500$ & $1(2 \%)$ & $0(0 \%)$ & $0(0 \%)$ & $0(0 \%)$ \\
\hline Total & $7(14 \%)$ & $32(64 \%)$ & $11(22 \%)$ & $50(100 \%)$ \\
\hline
\end{tabular}




\section{Economic Profile of Waste Collector Children}

\section{i. Household Income}

In some cases, the family members of the respondents are also involved in waste collection. Therefore, the family income of the respondents can be classified into two categories, income from waste collection and income from other sources. From waste collection, the family income varies from BDT 70 to BDT 800 per day depending on the number of family members involved and the age of the person collecting waste (Table 4). From other sources, the income ranges from BDT 500 to BDT 550 per day. On average, the household income per day is BDT 573.8.

Table 4: Daily family income (in BDT) of the waste collector children

\begin{tabular}{ccccc}
\hline \multirow{2}{*}{ Source of Income } & \multicolumn{2}{c}{ Gender } & \multirow{2}{*}{ Total average } \\
\cline { 2 - 4 } Waste & Minimum & 70 & 70 & \multirow{2}{*}{ Female } \\
collection & Maximum & 800 & 800 & \\
\multirow{3}{*}{ Others source } & Minimum & 0 & 0 & \multirow{2}{*}{138} \\
& Maximum & 550 & 500 & \multirow{2}{*}{ Total income } \\
& Minimum & 320 & 250 & 573.8 \\
& Maximum & 900 & 800 & \\
\hline
\end{tabular}

\section{ii. Household Poverty Status}

Based on the average family size of 4.16 members, per person per day income is BDT 137.93, which is equivalent to USD 1.7 (considering the exchange rate of USD 1 to BDT 80). Therefore, these people are marginally above the poverty line of USD 1.25 per person per day. However, $16 \%$ of the households of the waste collector children are below the poverty line.

\section{iii. Household Savings and Borrowings}

Among the households of the waste collector children, $18 \%$ have savings, and $24 \%$ have loans. Among those who have loans, $8 \%$ also have some savings. The maximum amount of savings is BDT 20,000 and the average savings is BDT 2,870. The maximum amount of those who have loans is reported as BDT 20,000 while the average loan is BDT 1,696. The majority of the respondents are in vulnerable situations, as they do not have any savings.

\section{Profile of Waste Collection}

\section{i. Reasons to Engage in Waste Collection}

There are many reasons for the children's engagement in waste collection such as to become independent, or to get rid of poverty, or for engaging in income generating activity, or those who have become street children due to family problems or other problems like separation of parents, orphan, family pressure, and affected by natural disaster (Table 5). However, most of them are engaged in this activity for economic improvement or poverty reduction. 
Table 5: Reasons to engage in waste collection

\begin{tabular}{lccc}
\hline \multicolumn{1}{c}{ Reasons } & Female & Male & Total \\
\hline Become independent & $2(4 \%)$ & $0(0 \%)$ & $2(4 \%)$ \\
Affected by natural disaster & $2(4 \%)$ & $2(4 \%)$ & $4(8 \%)$ \\
Orphan & $2(4 \%)$ & $3(6 \%)$ & $5(10 \%)$ \\
Family pressure & $2(4 \%)$ & $0(0 \%)$ & $2(4 \%)$ \\
Economic & $14(28 \%)$ & $18(36 \%)$ & $32(64 \%)$ \\
Drug & $1(2 \%)$ & $0(0 \%)$ & $1(2 \%)$ \\
Separation of parents & $2(4 \%)$ & $1(2 \%)$ & $3(6 \%)$ \\
Poverty & $8(16 \%)$ & $14(28 \%)$ & $22(44 \%)$ \\
\hline
\end{tabular}

\section{ii. Involvement with Waste Collection}

On an average, children start to collect waste from 10.54 years of age, and the range of starting age for waste collection is 6-13 years old. Among the respondents, on an average, children are engaged in waste collection for 2.12 years and the range of engagement in waste collection is $1-5$ years.

\section{iii. Types of Waste Collection}

The waste collectors collect several types of waste and sell it in two different ways. They may sell the total product at a fixed price or sell product by product. For a lump sum fixed price, the price depends on the size of the collection. The price of a small case is BDT 50 while a mega case is BDT 400 per case. However, in terms of specific material, the price of each material varies, ranging from BDT 3 to BDT 400 per kg (Table 6).

Table 6: Price list of Collected Waste

\begin{tabular}{lclc}
\hline \multicolumn{1}{c}{ Product } & BDT / per kg & \multicolumn{1}{c}{ Product } & BDT / per kg \\
\hline Iron & 22 & High quality plastic & 30 \\
Copper & 400 & Coconut wood & 5 \\
Bronze & 300 & Medium quality plastic & 6 \\
Silver & 120 & Low quality plastic & 3 \\
Borne & 7 & Car tire & 30 \\
Shoes / Lather & 7 & Energy drinks bottle & 15 \\
Glass & 3 & Poly of liquate milk & 25 \\
Tin & 20 & Electronic parts & 25 \\
\hline \multicolumn{1}{c}{ Case Size } & BDT / per case & & Case Size \\
\hline Small & 50 & Large & BDT / per case \\
Medium & 200 & Mega & 300 \\
\hline
\end{tabular}

Among the respondents, $26 \%$ of the children also collect food from the waste items (Figure 1). This shows a very alarming economic status or poverty status. This food may cause diseases and serious health issues. 


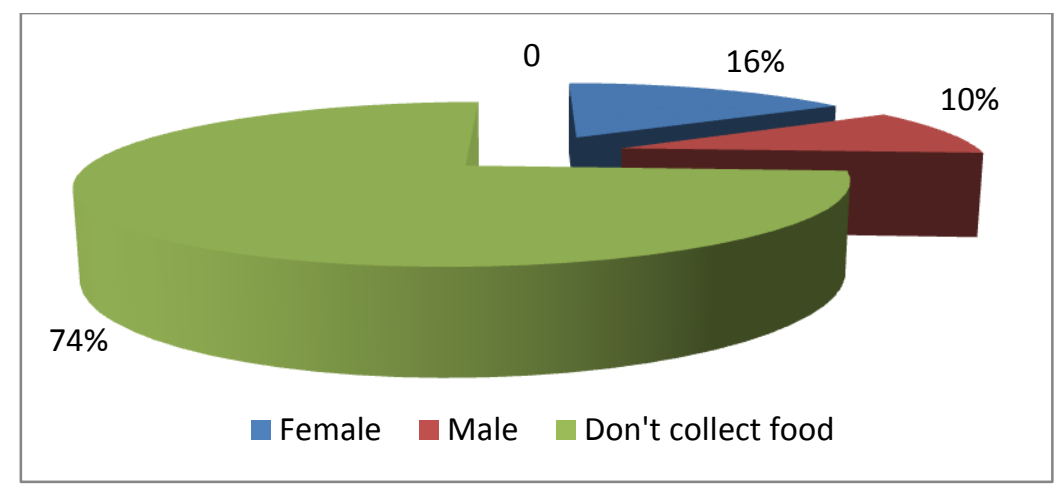

Figure 1: Food collector children from the waste

\section{iv. Income from Waste Collection}

In the majority of cases, the children earn from BDT 40 to BDT 150 per day from waste collection (Table 7). The male children earn slightly higher than the female. The earning range for the female children is BDT 40-119 and for the male children, it is BDT 40-150. The average income of male children is BDT 86, and female children is BDT 67.75 per day, and the total average income of the children is BDT 78.70 per day.

Table 7: Value (BDT) of waste collection per day

\begin{tabular}{|c|c|c|c|}
\hline \multirow{2}{*}{$\begin{array}{c}\text { Earning range } \\
\text { BDT }\end{array}$} & \multicolumn{2}{|c|}{ Gender } & \multirow{2}{*}{ Total } \\
\hline & Female & Male & \\
\hline $40-59$ & $4(8 \%)$ & $7(14 \%)$ & $11(22 \%)$ \\
\hline $60-79$ & $11(22 \%)$ & $5(10 \%)$ & $16(32 \%)$ \\
\hline $80-99$ & $4(8 \%)$ & $3(6 \%)$ & $7(14 \%)$ \\
\hline $100-119$ & $1(2 \%)$ & $11(22 \%)$ & $12(24 \%)$ \\
\hline $120-139$ & $0(0 \%)$ & $1(2 \%)$ & $1(2 \%)$ \\
\hline $140-150$ & $0(0 \%)$ & $3(6 \%)$ & $3(6 \%)$ \\
\hline Total & $20(40 \%)$ & $30(60 \%)$ & $50(100 \%)$ \\
\hline
\end{tabular}

\section{v. Spending the Income of Waste Collection}

Among the waste collector children, $78 \%$ spend their income on their family, while $10 \%$ spend the entire money for themselves (Figure 2). Among them, 12\% spend the income for family and save some of their income.

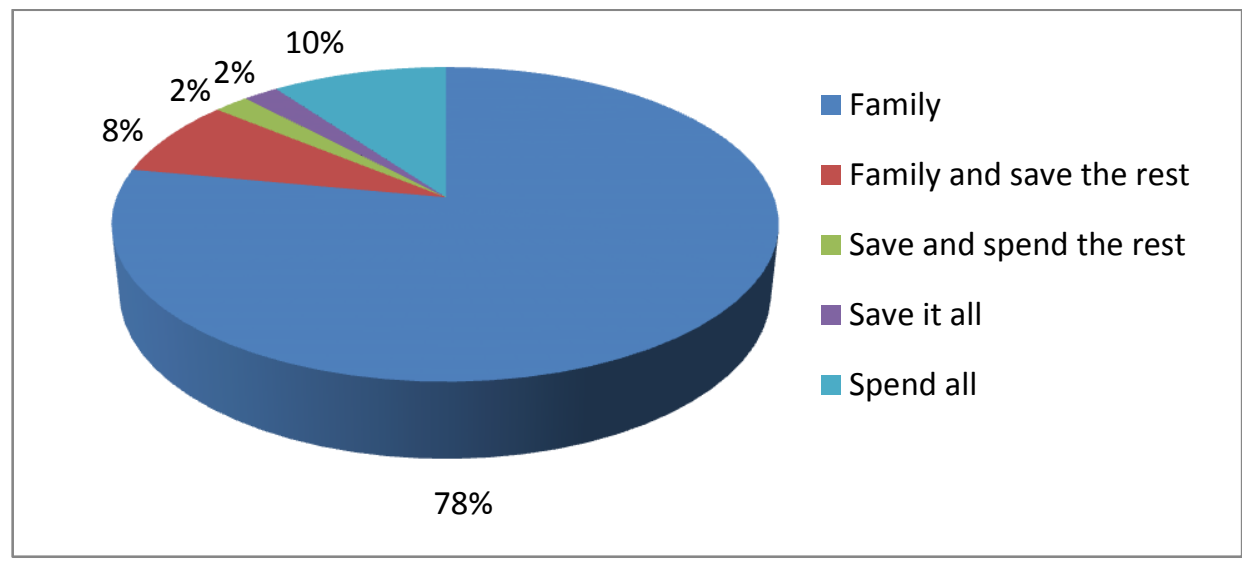


Figure 2: Sources of using the income from waste collection

\section{vi. Problems of Waste Collection Children}

Waste collection children face several difficulties such as occupational measures, nature of work, family pressure for earning, oppression by senior waste collectors, etc. Based on the opinion of the street children, $20 \%$ of the children do not face any problems, $34 \%$ of the children are concerned about their occupational measures or the type of occupation in which they are involved, $38 \%$ of the children face problems due to the nature of work, and $8 \%$ of the children are dominated or oppressed by senior waste collectors (Table 8).

Table 8: Problems face by children engaging in waste collection

\begin{tabular}{ccccc}
\hline Gender & No problems & $\begin{array}{c}\text { Occupation } \\
\text { measures }\end{array}$ & $\begin{array}{c}\text { Nature of } \\
\text { work }\end{array}$ & $\begin{array}{c}\text { Oppression by senior } \\
\text { waste collectors }\end{array}$ \\
\hline Female & $3(6 \%)$ & $7(14 \%)$ & $7(14 \%)$ & $2(4 \%)$ \\
Male & $7(14 \%)$ & $10(20 \%)$ & $12(24 \%)$ & $2(4 \%)$ \\
\hline Total & $10(20 \%)$ & $17(34 \%)$ & $19(38 \%)$ & $4(8 \%)$ \\
\hline
\end{tabular}

\section{Summary and Recommendations}

This study looked at the socioeconomic profiles of the poor children engaged in waste collection in Dhaka City, Bangladesh. The study made a survey on 50 waste collector children from the Matuail landfill in Dhaka. Among them, $40 \%$ of the respondents were female and $60 \%$ of the respondents were male. The age of the respondents ranged from 8-15 years. Almost half of them are from the age group of 14 to 15 years. Almost all of them go to either a government school or an NGO school that is operated by the Gram Bangla. Their education is free. Moreover, those who go to an NGO school also receive free food. Majority of the female children go to the NGO school.

Most of the respondents are living in tin shed house, where the average rent of the house is BDT 2,213 per month. The average family size of the respondents is 4.16 members, and the average earning members for their family are 3.08 persons. On average, the household income per day is BDT 573.8, and per person is BDT 137.93. Therefore, on an average these people are marginally above the USD 1.25 poverty line. However, $16 \%$ of the households are below the poverty line. Among the respondents, $18 \%$ of the households have savings and $24 \%$ have loan borrowings. The average range of savings per household is BDT 2,870, and the average loan is BDT 1,696.

In a majority of the cases, the children earn BDT 40-150 per day from waste collection. The male respondents earn slightly higher than the female respondents. The family members of these waste collector children are also often involved in waste collection. The family income from waste collection varies from BDT 70 to BDT 800 per day. These children have been waste collecting at least from the age of 6 years, and the average age for starting waste collection is around 10.54 years. Among the surveyed children, on an average they have been engaged in waste collection for 2.12 years. They collect different types of products such as waste that has market value, and $26 \%$ of the children also collect food from the waste, which is a matter of serious health issue. 
Majority of waste collector children are living with their parents. The occupations of their parents are not secured in terms of stability of income and continuity. Low income of the parents causes pressure on the children to start working at an early age. Majority of the parents are working in landfill areas and the children also follow them. The working areas in the landfill are difficult for them in terms of being a hazardous environment and lacking safety conditions, which are harmful to the children's health, mental and physical development. Many of the waste pickers do not even wear any protective clothing. Although a few of them wear gloves, these gloves are collected from the medical waste. This is a rather sensitive issue as many of them are already affected by several diseases. However, they are still involved in this hazardous activity due to the poor economic condition and poverty.

Nevertheless, it is a good sign that the majority of the children are going to school and almost half of them want to leave this activity and would like to study full time, and the other half want to change this profession. Still majority of these children are unaware of the health impacts of waste collection and are not aware of the free medical services facilities of the government. The parents of these children are also unaware about the basic rights of the children. As a result, the children are often deprived of their basic human rights. Therefore, the children and their parents need training and awareness building programs. They also need better health care and better medical facilities including free medicine, medical camps and first aid training, mobile medical and free medical services. Moreover, improving the economic status of these people and reducing poverty is the most sustainable solution for this problem.

\section{References}

Khan, M.A. (2000) "Health and Living Conditions of Child Labourers: A Study in Dhaka City in Bangladesh", The Department of Geography of Norwegian University of Science and Technology (NTNU) Trondheim, Norway.

Kilbride, P., Suda C.A., Njeru, E., \& Kariuki, P. (2000) Street Children in Kenya: Voices of Children in Search of a Childhood. Bergin \& Garvey. Westport, Connecticut, London.

Landrigan, P.J. (1998) "Vulnerable Populations, International Occupational and Environmental Medicine”, Jessica A. Herzstein (editor) et al., Mosby, Missouri, United State.

Sarkar, P. (2003) "Solid Waste Management In Delhi - A Social Vulnerability Study" International Conference on Environment and Health, Chennai, India, 15-17 December, 2003. Chennai: Department of Geography, University of Madras and Faculty of Environmental Studies, York University. Pages 451-464.

Shah, S.A.A. (2007) "Solid waste collection \& segregation: Health \& Protection risks of waste collector in Quetta, 8th International Conference "Waste Management, Environmental Geotechnology and Global Sustainable Development (ICWMEGGSD'07 - GzO'07)" Ljubljana, Slovenia.

UNICEF. (1990) "Children and development in the 1990s": A UATICEF sourcebook. Proceedings of the World Summit for Children. New York: United Nations Children's Fund.

WIEGO. (2013) Women in Informal Employment: Globalizing and Organizing "Waste Pickers: The Right to Be Recognized as Workers" International Labour Conference, June 2013. 